\title{
La fundación de la Sociedad Colombiana de Endocrinología
}

\section{Antonio Ucros Cuellar $†$}

Presidente de la Sociedad Colombiana de Endocrinología 1973 -

1974

Muy estimado señor Director:

$\mathrm{P}$ erdone que use el sistema epistolar para atender a su solicitud de escribir el editorial para la revista de nuestra sociedad; este estilo literario me da la ilusión de estar relatándole a alguien a quien mucho aprecio, la pequeña y la grande historia de la Sociedad Colombiana de Endocrinología.

Por allá en los años 49, Rodrigo Durán y yo, caminábamos por la Gran Vía; para escampar de la ventisca que venía del Guadarrama, entramos a Chicote a calentarnos el cuerpo y recrear la vista. Allí, al calor de un fino de Jerez, nació la inquietud de agrupar a los Endocrinólogos Colombianos y formar una Sociedad Científica. De regreso a Bogotá la idea se concretó. Convocamos a Tomás Quintero y a Guillermo Fisher, quienes habían sido profesores de muchos de nosotros; a Hernán Mendoza, que venía de Montreal de trabajar con Selye; a Luis Callejas, egresado de Bruselas; Alfredo Laverde de París y a los del grupo de Marañón que éramos los más, muchos de ellos pertenecientes a la primera generación de médicos Javerianos. Esta primera etapa fue reseñada en forma exquisita por Alonso Gutiérrez, miembro fundador, en un discurso conmemorativo. Poco después llegó Jaime Cortázar, de Boston, a enriquecer nuestras filas. Alberto Jamís en Barranquilla, Ivan Molina en Medellín y Ricardo Suárez en Cali, comenzaron a conformarle a nuestra Sociedad un carácter nacional.

El año 53 marcó un hito en la historia de la Sociedad: se efectuó un curso de Endocrinología promovido por Unidia, al cual asistieron como ponentes Henry Turner, de Oklahoma, Lawson Wilkins, de Baltimore, y Ernesto Salgado, en ese entonces discípulo amado de Selye; este cursillo le dio más ubicación a la ya coherente Sociedad, le abrió perspectivas internacionales y en gran parte le modificó sus derroteros. Para entonces ya habían entrado a la Sociedad Efraím Otero, Bernardo Reyes y Julio Gómez; se había ampliado su ingreso a médicos no Endocrinólogos y gracias a eso cuenta en su nómina a Mario Sánchez Medina, a César Mendoza, a Mario Gaitán Yanguas y a Guillermo López Escobar. Esta fue la infraestructura de la Sociedad; de allí en adelante las cosas fueron más fáciles.
Se fundó la Revista, que ha persistido contra viento y marea, y muchos de nosotros hemos sido sus directores; a esta actividad la han caracterizado la buena voluntad, la tenacidad y la escasez de dinero. Varios artículos han sido reproducidos en revistas extranjeras y en el Libro del Año; es la más antigua y regular Revista en su género en Latinoamérica.

Se hizo un estudio en Guaduas sobre Cretinismo, que le valió a la Sociedad el premio Alejandro Ángel; se intervino en múltiples cursillos y simposios de Divulgación y Educación Médica continuada. Pero la actividad más importante, a mi juicio, es la Reunión Anual de la Sociedad que siempre se ha hecho en una ciudad distinta del país, obteniendo en esta forma un objetivo de divulgación, actualización y promoción de la especialidad que se compagina muy bien con su filosofía docente.

Para esa época ya eran miembros de número usted, doctor Ahumada, y algo más tarde Rafael Gómez Cuevas, Alfredo Jácome, Rafael Almánzar, en Bogotá; en Medellín, Iván Duque y Arturo Orrego; Eduardo Gaitán y Fernando del Corral, en Cali; Manuel Manzanilla, de Caracas; Moisés Arteaga, de Cuenca; Paco Parra de Guayaquil; Pablo Fletcher, en Panamá, y más tarde, Luis Sobrevilla, de Lima.

La consecuencia inmediata y efectiva de la Sociedad tuvo su fruto en la individualización o lo que pudiéramos llamar "servicios" de Endocrinología que en forma concreta e independiente comenzaron a funcionar en los principales Hospitales del país. El primero de ellos fue el que se fundó en el Hospital de San José en 1950. Al poco tiempo comenzó a funcionar el del Instituto Nacional de Cancerología que fue el pionero en el uso de los Isótopos Radioactivos; el de San Juan de Dios y el de San Ignacio. Es necesario agregar a esta lista la Asociación Colombiana de Diabetes que es una prima hermana de nuestra Sociedad y a quien de paso debemos una hospitalidad afectuosa, permanente y gratuita. En el Hospital San Vicente de Medellín y en el Departamental de Cali se formaron núcleos fuertes y homogéneos que trabajan en el seno de la Universidad. Todos estos centros cuentan ya con un buen número de profesionales entrenados en la práctica de la Endocrinología y que son parte del aporte que la Sociedad ha dado a la Medicina Colombiana.

Pero la filosofía proselitista de la Sociedad no se conformó con lo obtenido; continuando con su idea expansiva, 
promovió y formó la Sociedad Bolivariana de Endocrinología para estudiar problemas comunes en un contexto académico, económico y cultural semejante. Se convocó al bloque de países ligados a la figura histórica de Bolívar y regularmente han venido reuniéndose los Endocrinólogos Bolivarianos para dialogar, discutir y solucionar sus propios problemas; como usted sabe, en este agosto se reunirá por quinta vez la Sociedad Bolivariana de Endocrinología en Bogotá, con programas de trabajo diseñados de acuerdo a nuestras prioridades y posibilidades.
Y para terminar esta larga carta, quiero hacer memoria de quienes fueron nuestros compañeros y pagaron su tributo a la vida; todos a su manera trabajaron por la idea; especialmente la gestión de Hernán Mendoza se destacó por la eficacia, resultado de su fuerte personalidad.

A gentes nuevas y mejor preparadas como usted, doctor Ahumada, corresponde hacer una crítica objetiva de estos 25 años de funcionamiento de la Sociedad Colombiana de Endocrinología. Mucha benevolencia y un poco de afecto es lo único que pretendemos de quienes seguirán nuestra obra.

\section{Referencias}

Tomado de la Revista de la Sociedad Colombiana

Endocrinología Vol. X No. 1 - Diciembre 1974. Pág. 5 y 6 